\title{
Prediction of Compaction Parameters of Khon Kaen Loess Soil ${ }^{\dagger}$
}

\author{
Prinya CHINDAPRASIRT ${ }^{1}$, Apichit KAMPALA ${ }^{2, *}$, \\ Anukun ARNGBUNTA ${ }^{2}$ and Suksun HORPIBULSUK ${ }^{3}$
}

\author{
${ }^{1}$ Sustainable Infrastructure Research and Development Center, Department of Civil Engineering, \\ Faculty of Engineering, Khon Kaen University 40002, Thailand \\ ${ }^{2}$ Department of Civil Engineering, Faculty of Engineering, Rajamangala University of Technology Isan, \\ Khon Kaen Campus, Khon Kaen 40000, Thailand \\ ${ }^{3}$ Center of Excellence in Innovation for Sustainable Infrastructure Development, School of Civil \\ Engineering, Suranaree University of Technology, Nakhon Ratchasima 30000, Thailand
}

('Corresponding author's e-mail: apichit.ku@rmuti.ac.th)

Received: 19 June 2019, Revised: 22 January 2020, Accepted: 9 February 2020

\begin{abstract}
Soil stratum in Khon Kaen province, located in Northeast of Thailand, is well-known as a winddeposited fine-grained soil (i.e. silty sand and silty clay). It is normally called "Loess or Khon Kaen Loess". This soil in disturbed stage is usually extracted from the borrow pit and subsequently compacted for infrastructure applications. The compaction resulted in silty sand or silty clay aggregation with unpredictable properties. Although required for infrastructure design, studies on Khon Kaen Loess are limited. Thus, this research examines the compaction behavior and predicts soil parameters at various clay contents under a series of compaction energy on Khon Kaen Loess. The results showed that the maximum dry unit weights of samples could be related to the dry unit weight at plastic limit (PL), while the optimum water content (OWC) was correlated linearly with the PL. The samples with higher PL presented the higher OWC. In addition, the maximum dry unit weight and OWC of samples could be estimated using the developed equations validated with the other research results.
\end{abstract}

Keywords: Loess, Compaction energy, Plastic limit, Optimum water content, Maximum dry unit weight

\section{Introduction}

Soil stratum in Khon Kaen province in the Northeast of Thailand consists of 2 types of soil: 1) silty sand (SM) which is mostly found at a depth of $0-1.5$ and $5.0-8.0 \mathrm{~m}$, and 2) silty clay (CL) found at a depth of $1.5-5.0 \mathrm{~m}$ or between the silty sand layers at various depths. This SM layer is a small layer, deposited by wind and is normally called 'Loess' or 'Khon Kaen Loess'. The soil is generally a yellow fine-grained soil and consists of calcium rich element which results in the soil particle being bound together tightly. However, this characteristic is easily destroyed by the presence of moisture.

When this Loess is dried or compressed at an optimum water content (OWC), the bearing capacity of the soil is elevated to greater than $1000 \mathrm{kPa}$ with a permeability coefficient of $1 \times 10^{-5}$ to $1 \times 10^{-7} \mathrm{~cm} / \mathrm{s}$ and a linear shrinkage of $1 \%$. In wet condition, the bearing capacity is nevertheless decreased to be less than $50 \mathrm{kPa}$ and linear shrinkage is raised to $8-10 \%$ [1-6].

$\dagger$ Presented at the $2^{\text {nd }}$ International Symposium on Construction Innovation Research \& PhD Symposium: July 18-19, 2019. 
The silty clay is an inorganic soil with low-to-medium plasticity depending on the amount of clay minerals. In terms of engineering properties, the shear strength and permeability are typically low coinciding with high compressibility [7]. In natural condition, the layer of silty clay is adjacent to the layer of sandy silt. Therefore, when extracting the Loess from borrow pit, it is definitely mixed with silty clay.

In terms of compaction parameters, the OWC and the maximum dry density are prime parameters used in the design for engineering and construction performances. There have been many research papers suggesting the estimation of compaction parameters with regard to the index properties: Liquid Limit (LL) and Plastic Limit (PL) [8]. However, the estimation of aforementioned parameters at various compaction energies is still limited.

Therefore, this research aims to investigate the compaction behavior of the Loess with various clay contents and plastic limits between 14 and $30 \%$, as well as to derive an equation for the prediction of compaction parameters using physical properties such as PL and GS at various compaction energies (a) half of standard compaction, (b) standard compaction, (c) half of modified compaction and (d) modified compaction [9]. The output of this research will lay the foundation towards understanding the compaction behaviors of Loess with various clay contents. This also offers a predicting equation of the compaction parameters (maximum dry density and OWC) at various compaction energies and clay contents from the index properties.

\section{Materials and methods}

The soil samples used in this research were a mixture of Khon Kaen Loess (silty sand, SM) extracted at a depth of $1-3 \mathrm{~m}$ and clay (CL) at $3-4 \mathrm{~m}$ from the borrow pit in Ban Phai District, Mueang District, Khon Kaen Province, Thailand. The tested samples were Loess mixed with 10, 20, 30, 40, and $50 \%$ of clay by weight of dry soil. The Loess and clay were also tested and used as references. The grain size distributions of the tested soils are shown in Figure 1. The clay fraction (\% passing sieve No 200) of the studied soil samples varied from 15 to $67 \%$.

The basic properties of the samples are shown in Table 2. The increasing clay content of LL, PL and Plasticity index (PI) of the samples were noted. LL and PI of Khon Kaen Loess with various clay contents were plotted in the plasticity chart as shown in Figure 2. The results clearly demonstrated that the LL and PI were proportionally changed and related to the clay content. All (LL and PI) points positioned above A-line (the dividing line of clay and silt) and under U-line (the upper limit of the plasticity chart).

The basic tests on properties of Loess with various amount of clay are Specific gravity (ASTM D 854 - 14), Sieve analysis (ASTM D422 - 63(2007)e2), Liquid limit and Plastic limit (ASTM D4318 17e1), Standard Compaction test (ASTM D698 - 12e2) and Modified Compaction test (ASTM D1557 12e1). The amount of energy in compaction test for preparation of samples are shown in Table $\mathbf{1 .}$

Table 1 Energy in compaction.

\begin{tabular}{lc}
\hline \multicolumn{1}{c}{ Compaction } & Energy $\left(\mathrm{kJ} / \mathrm{m}^{3}\right)$ \\
\hline (a) Half of Standard compaction & 296 \\
(b) Standard compaction & 592 \\
(c) Half of Modified proctor & 1,346 \\
(d) Modified proctor & 2,693 \\
\hline
\end{tabular}




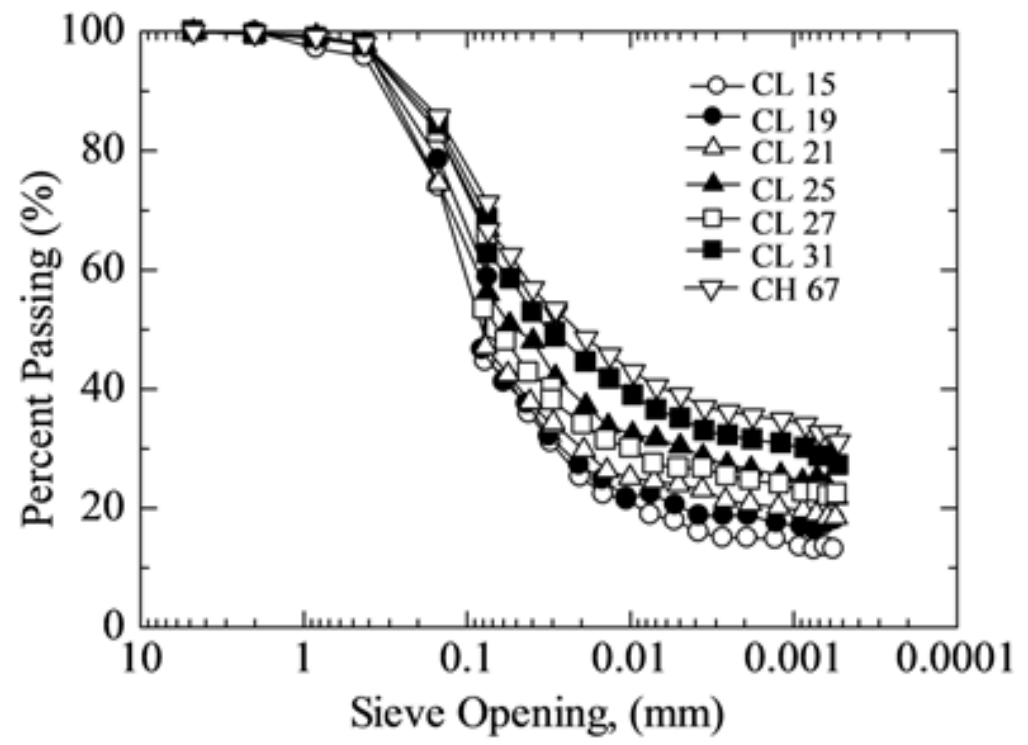

Figure 1 Grain size distribution of Khon Kaen Loess with various amount of clay.

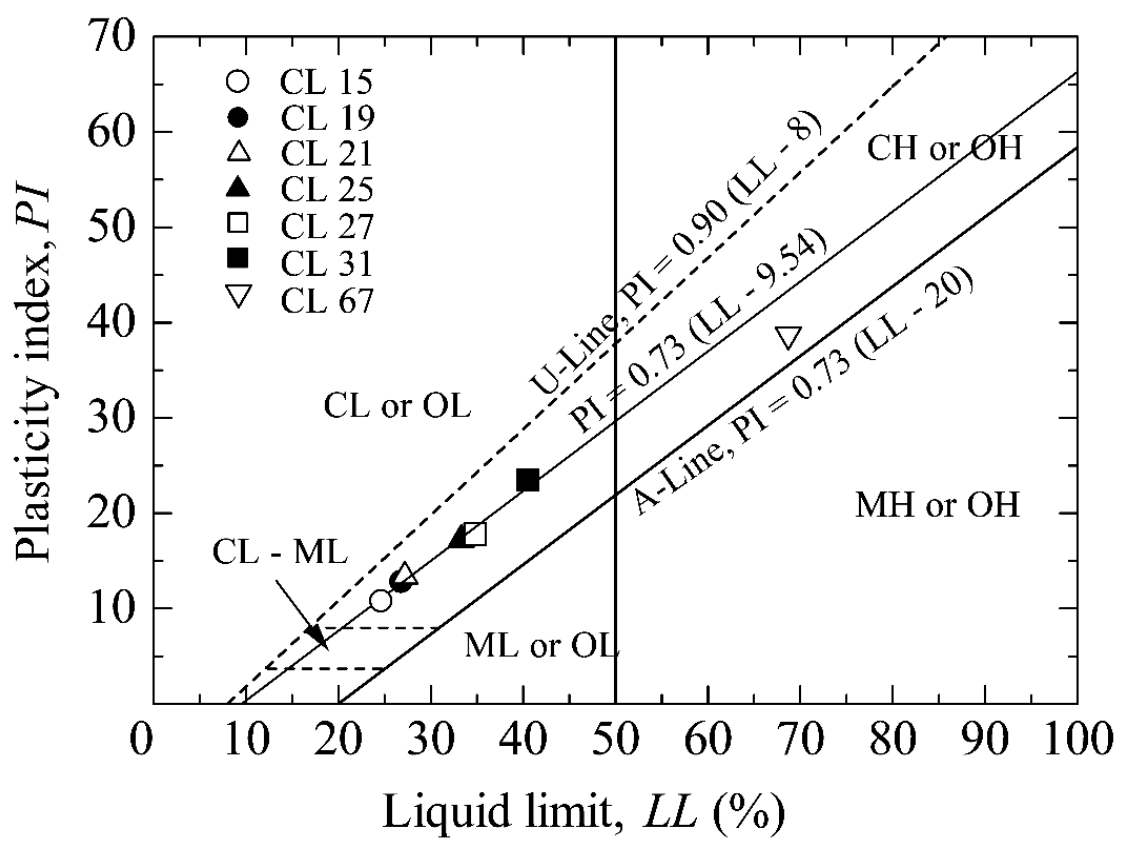

Figure 2 Correlation of plasticity index and liquid limit. 
Table 2 Physical properties of Khon Kaen Loess with various clay contents.

\begin{tabular}{cccccccc}
\hline $\begin{array}{c}\text { Samples } \\
\text { name }\end{array}$ & $\begin{array}{c}\text { Loess : } \\
\text { Clay }\end{array}$ & $\begin{array}{c}\text { Clay fraction } \\
\text { of soil (\%) }\end{array}$ & $\mathbf{G}_{\mathbf{s}}$ & $\begin{array}{c}\text { LL } \\
\mathbf{( \% )}\end{array}$ & $\begin{array}{c}\text { PL } \\
\mathbf{( \% )}\end{array}$ & $\begin{array}{c}\text { PI } \\
\mathbf{( \% )}\end{array}$ & $\begin{array}{c}\text { Soil } \\
\text { Classification }\end{array}$ \\
\hline CL 15 & $100: 0$ & 15.24 & 2.60 & 24.7 & 14.0 & 10.7 & SM \\
CL 19 & $100: 10$ & 18.78 & 2.62 & 26.8 & 14.1 & 12.7 & CL \\
CL 21 & $100: 20$ & 20.76 & 2.63 & 30.1 & 15.8 & 14.3 & CL \\
CL 25 & $100: 30$ & 24.69 & 2.65 & 33.2 & 16.0 & 17.2 & CL \\
CL 27 & $100: 40$ & 26.56 & 2.66 & 34.9 & 17.2 & 17.7 & CL \\
CL 31 & $100: 50$ & 31.49 & 2.67 & 40.6 & 17.2 & 23.4 & CL \\
CH 67 & $0: 100$ & 67.19 & 2.69 & 68.7 & 30.0 & 38.7 & CH \\
\hline
\end{tabular}

\section{Results}

The clay fraction in Loess (SM) was approximately $15 \%$ and the clay (CL) contained approximately $67 \%$ clay fraction as shown in Table 2 . The increase in CL content in the sample resulted in the increased LL and PL. The specific gravity $\left(\mathrm{G}_{\mathrm{s}}\right)$ of the sample also increased with increasing CL content as the $\mathrm{G}_{\mathrm{s}}$ of CL was 2.69, whereas the S.G. of Loess was slightly less at 2.60.

Figure 3 shows the correlation between the dry unit weights and the OWCs of Loess with various amount of CL of the compacted samples at (a) half of standard compaction, (b) standard compaction, (c) half of modified compaction, and (d) modified compaction. In actuality, the ZAV lines of different soil types will not be the same depending on the $G_{s}$. The ZAV line in Figure 3 was drawn using $G_{s}=2.65$ to show that the OWC is saturated near the plastic stage.

According to Figure 3, the maximum dry unit weights of each sample increased while the OWCs decreased with increasing compaction energy. For example, the maximum dry density values of mix CL21 were $17.0,17.0,18.7$ and $19.5 \mathrm{kN} / \mathrm{m}^{3}$ and the OWCs were $16.8,16.8,12.5$ and $11.5 \%$ for compacted samples (a), (b), (c) and (d), respectively.

Figure 4 shows the correlation between the OWC and PL of Loess with various amount of CL of the compacted samples (a), (b), (c) and (d). The relationships between OWC and PL of all compacted soil samples were linear and passed through the ordinate $(0,0)$. The relation could be expressed by Eq. (1).

$$
O W C=\mathrm{k}_{1} w_{P L}
$$

where $\mathrm{k}_{1}$ = a constant depending on the compaction energy, and

$\mathrm{W}_{\mathrm{PL}}=$ water content at the PL.

For all compaction energies, the OWC was related to PL; the soil samples with high PL had high OWC. For the soil samples with low PL, OWC was also low. The graphs of all compaction energies were similar but the slopes of each graph were different depending on the compaction energy. The compaction energy reduces the air voids between the soil particles, while the water facilitates the movement of the soil. Therefore, an increased in compacted energy resulted to the reduction in OWC and the reduction in slope of $k_{1}$. This was reflected by the $k_{1}$ value or slope of Eq. (1). $\mathrm{k}_{1}$ values were $1.03,0.92,0.86$ and 0.70 for compacted samples (a), (b), (c) and (d), respectively. The sample with lowest compaction energy had the highest $\mathrm{k}_{1}$ value representing the highest water content with corresponding PL. 

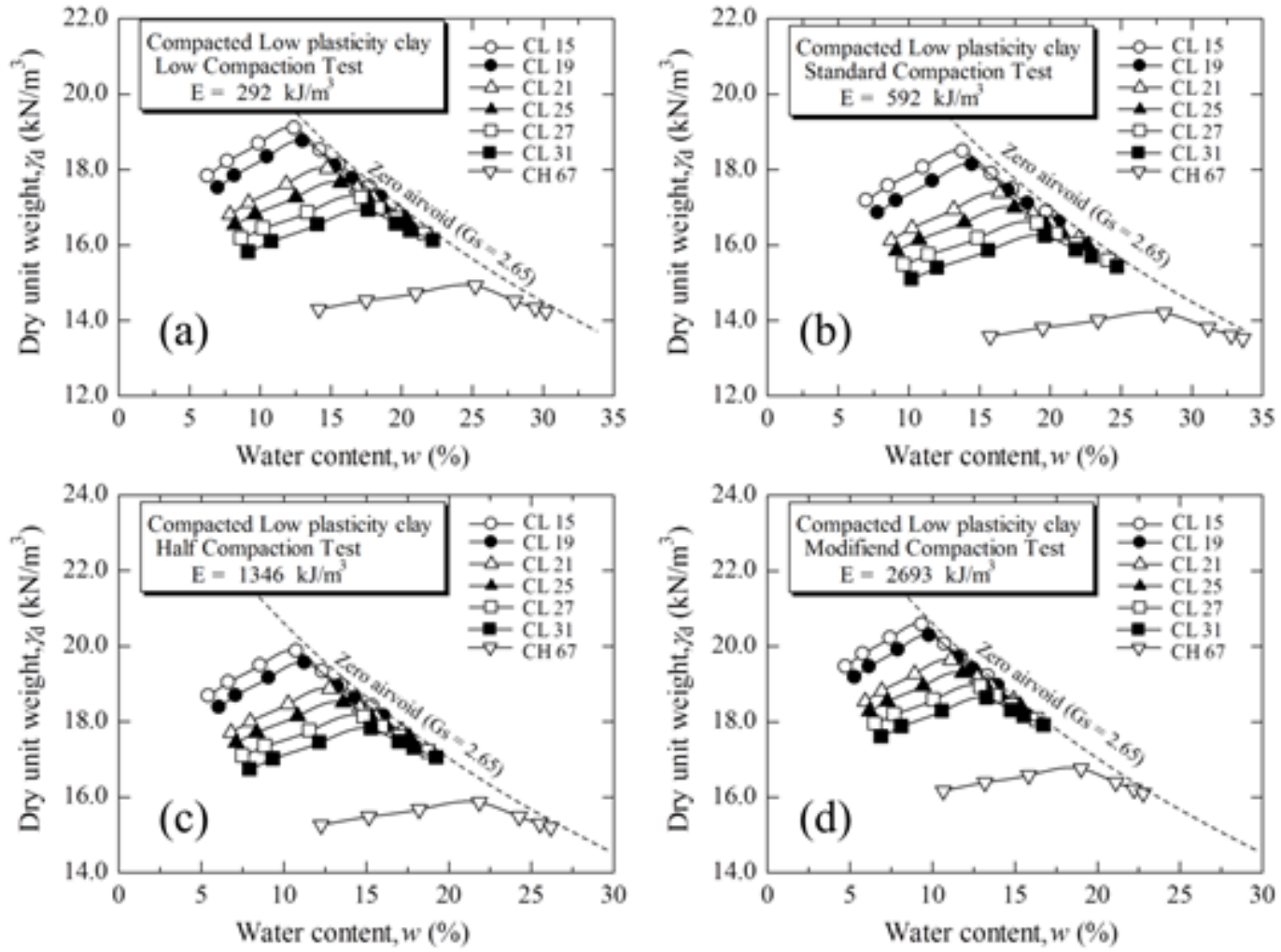

Figure 3 Correlation between the dry unit weights and OWCs of compacted samples (a), (b), (c) and (d). 


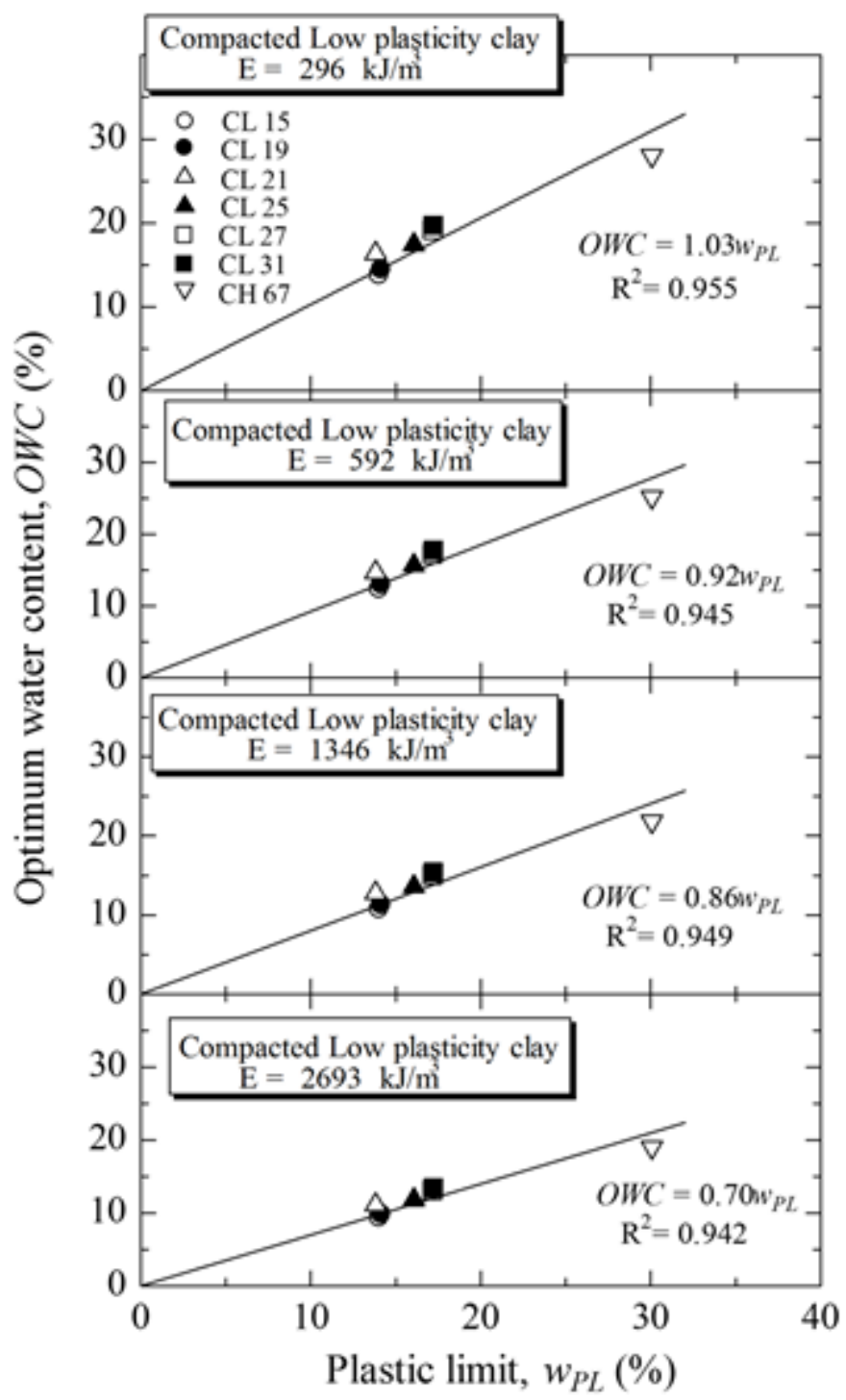

Figure 4 Correlation between OWC and PL of compacted samples (a), (b), (c) and (d).

Given $\mathrm{k}_{1}$ is the slope of the graph correlating between the OWC and PL of compacted samples (a), (b), (c) and (d). It was possible to generate a relationship between $\mathrm{k}_{1}$ and the compaction energy as shown in Figure 5 from the graph, $\mathrm{k}_{1}$ could be estimated if compaction energy is known.

$$
\mathrm{k}_{1}=0.63+0.06 \ln (E)
$$

where $E$ is compaction energy $\left(\mathrm{kJ} / \mathrm{m}^{3}\right)$. 
In summary, $\mathrm{k}_{1}$ could be obtained from Eq. (2) with known compaction energy (E). The OWC of the soil mixture could thus be obtained using $\mathrm{k} 1$ and PL of soil mixture.

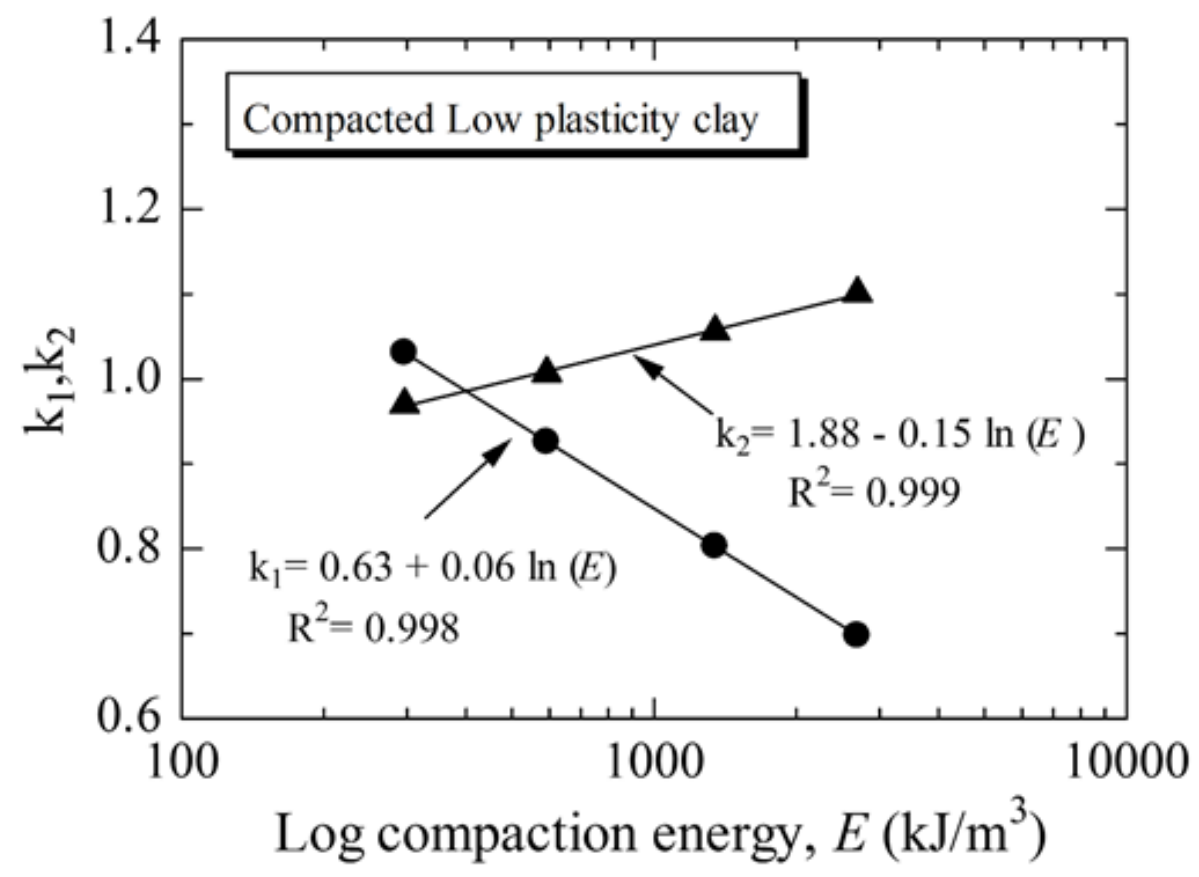

Figure 5 relationship of k1, k2 and compaction energy.

Figure 6 shows the relationship between the maximum dry unit weight and the dry unit weight at plastic limit of Loess with various CL contents under the series of compaction energy. The relationship could be expressed by Eq. (3). The maximum dry unit weight increased with increasing compaction energy. This linear relationship was related by the $\mathrm{k}_{2}$ value as shown in Eq. (4). The $\mathrm{k}_{2}$ values were 0.97 , $1.00,1.05$ and 1.15 for compacted samples (a), (b), (c) and (d), respectively.

$\gamma_{\mathrm{dw}_{P L}}=\frac{G s \cdot \gamma_{w}}{1+G s \cdot w_{P L}}$

where $\gamma_{d w_{P L}}$ is a dry unit weight at PL, determined by assuming degree of saturation at PL equals to 100 $\%$ and $\mathrm{E}\left(\mathrm{kJ} / \mathrm{m}^{3}\right)$. 


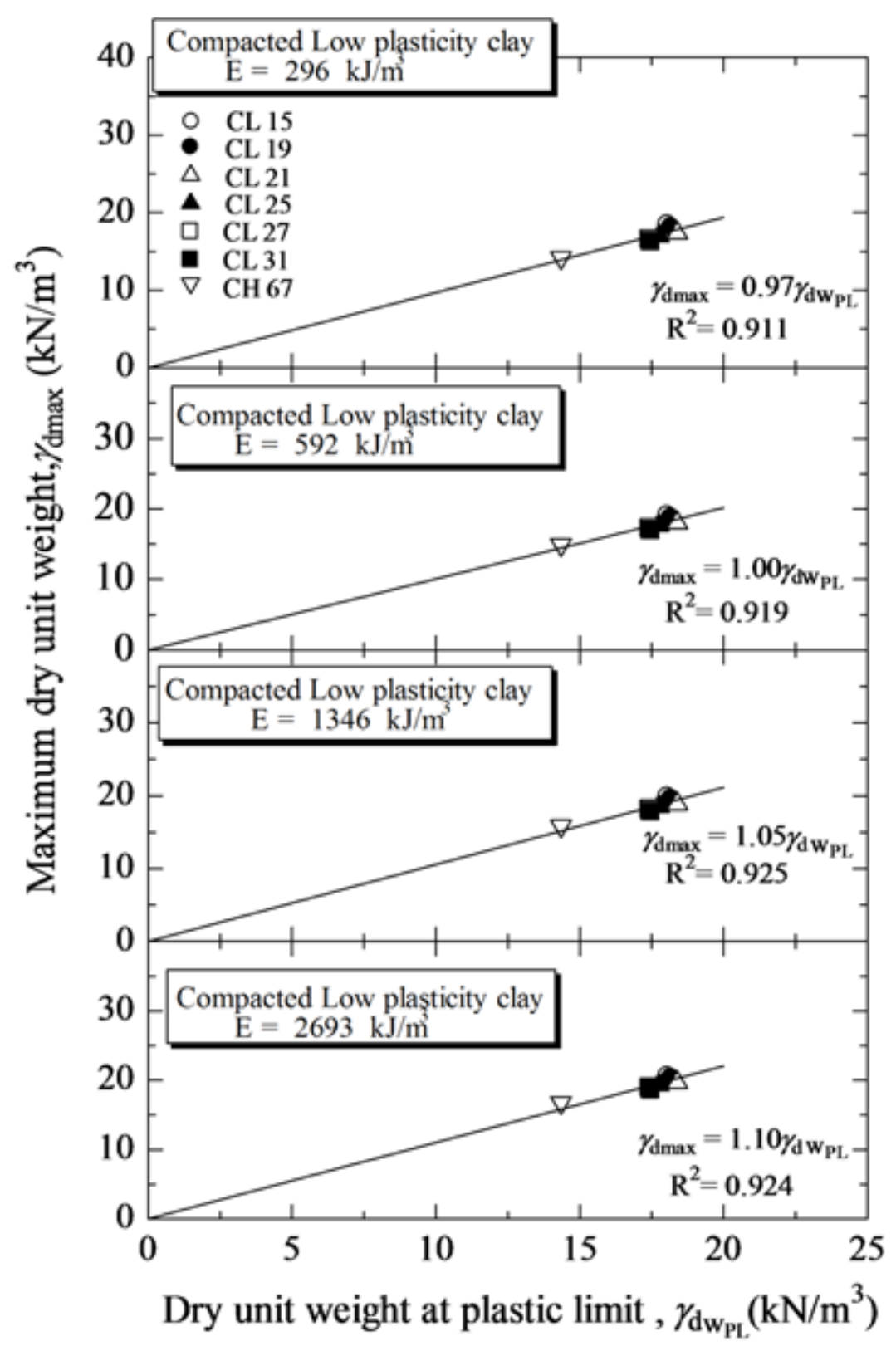

Figure 6 Relationship between maximum dry unit weight and dry unit weight at PL.

$\gamma_{d \max }=\mathrm{k}_{2} \gamma_{d w_{P L}}$

where $\mathrm{k}_{2}$ is a constant depending on compaction energy.

The $\mathrm{k}_{2}$ value was dependent on compaction energy and could be determined from Eq. (5) as also shown in Figure 5. 
$\mathrm{k}_{2}=1.88-0.15 \ln (E)$

where $E$ is compaction energy $\left(\mathrm{kJ} / \mathrm{m}^{3}\right)$.

Likewise, for all compaction energies, the results indicated that the maximum dry unit weight increased linearly and was also related to the dry unit weight at PL. The difference was merely on the slope of the graph with different compaction energies. For a given $k_{2}$, the relationship between the dry unit weight and the compaction energy could be established. Therefore, the known compaction energy enables the dry unit weight of Loess with various clay content to be determined.

\section{Discussion}

According to the compaction graphs of Loess with various CL contents (Figure 3), the dry unit weight decreased, while OWC increased with increasing CL content. Figure 3 also indicated that the compaction curve of sample with low CL content showed a distinct peak at OWC, but that with high CL content showed only moderate peak. This confirmed that the sample with low CL content was sensitive to the change in water content in terms of the dry unit weight.

In addition, according to the properties of Loess with various CL contents (Table 2), LL and PL were also related to the CL content of sample. Since the basic and engineering properties of fine-grained soil vary according to the type, the amount of clay mineral, pore fluid and soil-water interaction [10,11], the activity index and liquidity index are the parameters that indicate the type of clay minerals. [12] and the state of water in the soil mass [13]. The values of activity index and liquidity index are estimated from consistency limit (LL, PL). Therefore, in this research, the LL and PL are important variables controlling the OWC and maximum dry unit weight of soil [14-19].

The OWC of compacted soil samples was found to be closed to the water content at plastic index as shown in Figure 3 that the OWC is approximately on the ZAV. Therefore, the PL is taken in estimating the compaction parameters at various compaction energies of the Loess with various CL contents [9]. Gurtug and Sridharan [9] suggested the relationship between the OWC and PL (see Figure 4), and the relationship between the maximum dry unit weight and the dry unit weight at PL (see Figure 6). The compaction parameters were dependent on the compaction energy. Consequently, the derived constants correlated with compaction energy (Figure 5). The linear relation could be obtained using a semi-logarithm plot.

The data totaling 49 samples of fine-grained soils from the work of Nagaraj and Suresh [20], Punrattanasin [21], Maa et al. [22], Kim et al. [23], Yodsa-nga et al. [24] and Mosallamy et al. [25] were used in the estimation of OWC and maximum dry unit weight using equations 1 to 5 (see Table 3). It was found that the tested OWC could be estimated using the equations with $\mathrm{r}^{2}$ of 0.943 (see Figure 7). For maximum dry unit weight, good estimation was also obtained with $\mathrm{r}^{2}$ of 0.795 (see Figure 8). The values of $\mathrm{r}^{2}=0.943$ and 0.795 show that the estimation accuracy is $93.4 \%$ for OWC of the compacted soil and $79.5 \%$ for the maximum dry unit weight. The outcome of this research, thus shows that the empirical equations could be developed and used to predict the physical and engineering properties of silty soils or Loess mixed with silty clay. 
http://wjst.wu.ac.th

Table 3 Results of testing data used in the prediction of OWC and maximum dry unit weight.

\begin{tabular}{cccl}
\hline \multicolumn{2}{c}{ Compaction } & Testing data & \multicolumn{1}{c}{ Researcher } \\
\hline Standard & Energy $\left(\mathbf{k J} / \mathbf{m}^{\mathbf{3}}\right)$ & & \multicolumn{1}{c}{ Yodsa-nga et al., (2012) } \\
& 592 & 1 & Kim et al., (2013) \\
& & 1 & Mosallamy et al., (2016) \\
\hline Standard proctor & 802 & 3 & Ma et al., (2017) \\
\hline Reduced modified proctor & 1,238 & 1 & \\
& 2,013 & 1 & Nagaraj and Suresh, (2018) \\
& 2,693 & 1 & Punrattanasin, (2005) \\
& & 39 & Ma et al., (2017) \\
\hline
\end{tabular}

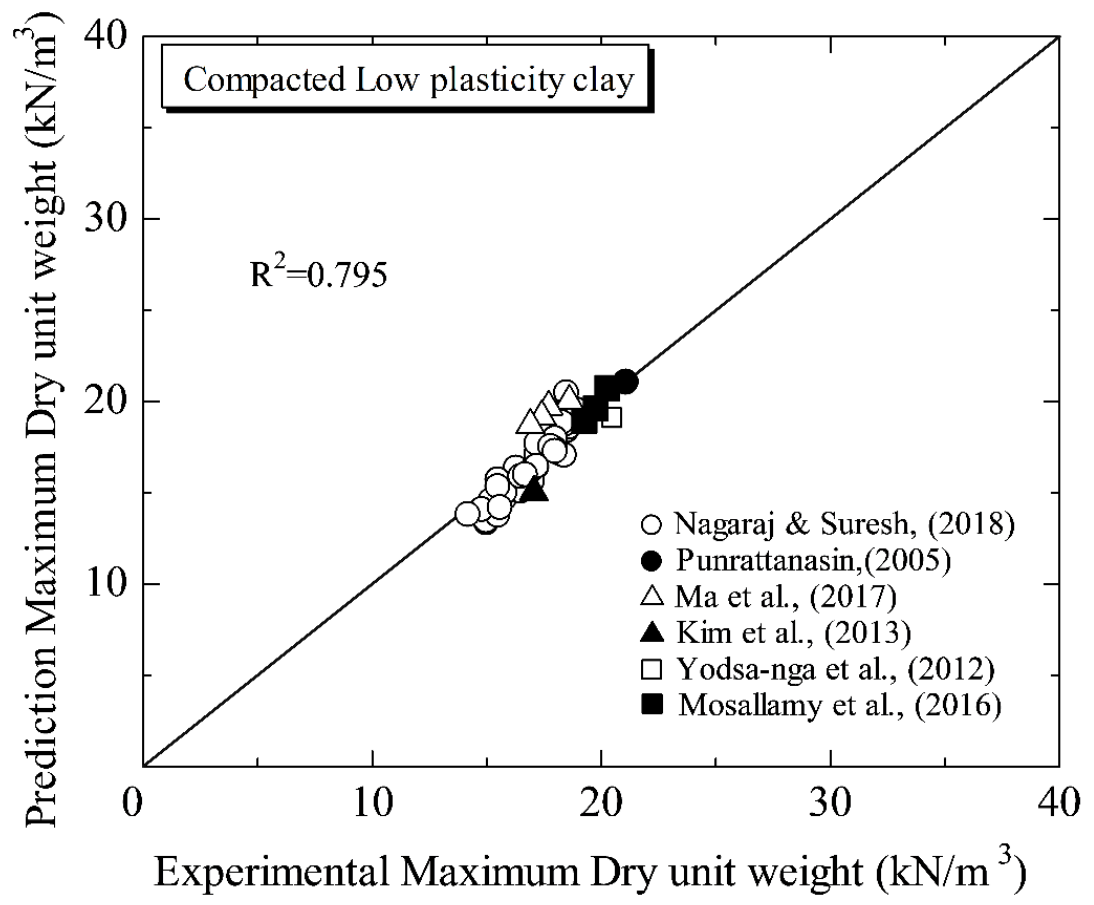

Figure 7 Correlation between laboratory and prediction OWC of compacted low plasticity clay. 


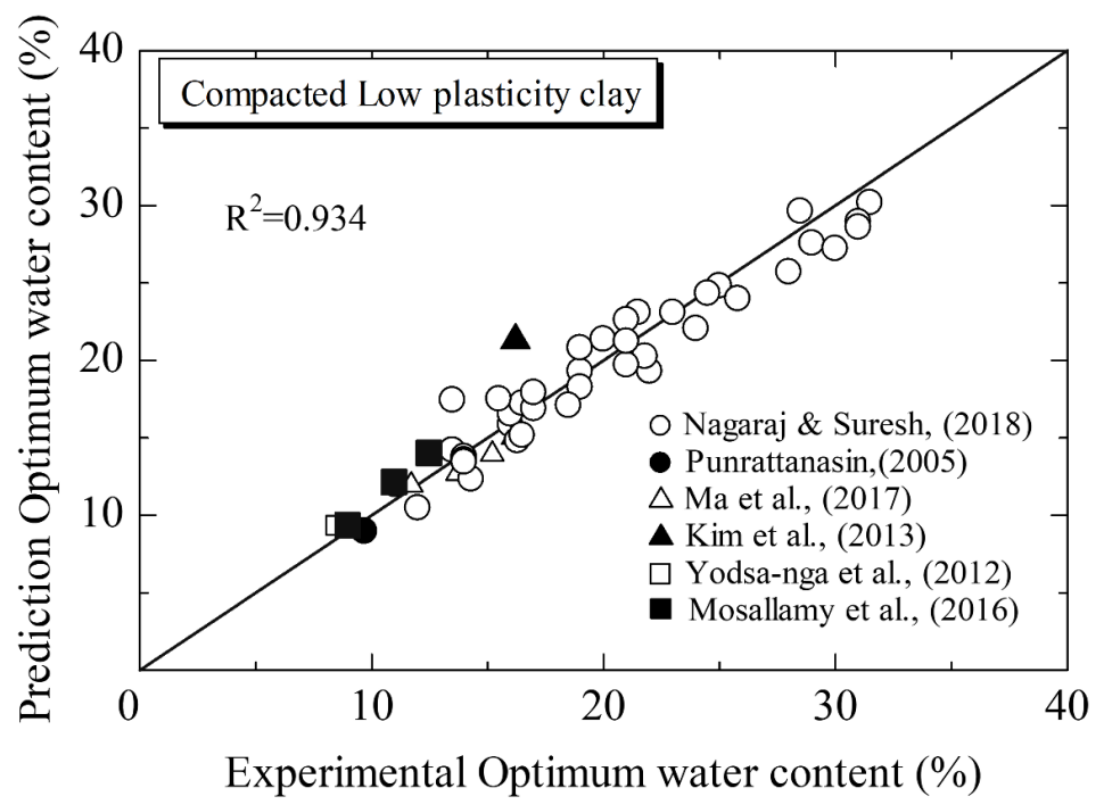

Figure 8 Comparison between laboratory and prediction maximum dry unit weight of compacted low plasticity clay.

\section{Conclusions}

The study of the compaction behavior of Khon Kaen Loess with various clay contents and the prediction of compaction parameters can be concluded as follows:

1. The maximum dry unit weight of Khon Kaen Loess decreased when the clay contents and the OWC increased in their contents.

2. The OWC of Khon Kaen Loess with various amount of clay has a linear relationship with PL. Thus, the OWC in relation to the compaction energy could be calculated using the equation $O W C=w_{P L}(0.63+0.06 \ln (E))$.

3. The maximum dry unit weight increased with an increased of dry unit weight at PL. The linear relationship $\mathrm{n} \gamma_{d \max }=(1.88-0.15 \ln (E)) \gamma_{d w_{P L}}$ could be used to estimate the dry unit weight of Khon Kaen Loess with various clay contents.

\section{Acknowledgements}

The authors acknowledge the financial support provided by Rajamangala University of Technology Isan. The first author would like to acknowledge the support of the Thailand Research Fund through Distinguished Research Professor Grant DPG 6180002.

\section{References}

[1] P Li, H Qian and J Wu. Environment: Accelerate research on land creation. Nature 2014; 510, 2931.

[2] JC Lommler and $\mathrm{P}$ Bandini. Characterization of collapsible soils. In: Proceedings of the International Foundations Congress and Equipment Expo 2015. San Antonio, Texas, 2015.

[3] AA Al-Rawas. State-of-the-art review of collapsible soils. J. Eng. Sci. Tech. Rev. 2008; 1, 115-35. 
http://wjst.wu.ac.th

[4] MS Nouaouria, M Guenfoud and B Lafifi. Engineering properties of loess in Algeria. Eng. Geol. 2008; 99, 85-90.

[5] N Phien-wej, T Pientong and AS Balasubramaniam. Collapse and strength characteristics of loess in Thailand. Eng. Geol. 1992; 32, 59-72.

[6] TG Ryashchenko, VV Akulova and MA Erbaeva. Loessial soils of Priangaria Transbaikalia, Mongolia, and northwestern China. Quatern. Int. 2008; 179, 90-5.

[7] S Horpibulsuk, S Shibuya, K Fuenkajorn and W Katkan. Assessment of engineering properties of bangkok clay. Geotechnique 2007; 44, 173-87.

[8] S Horpibulsuk, W Katkan and A Apichatvullop. An approach for assessment of compaction curves of fine-grained soils at various energies using a 1-point test. Soils. Found. 2008; 48, 115-26.

[9] Y Gurtug and A Sridharan. Compaction behaviour and prediction of its characteristics of fine grained soils with particular reference to compaction energy. Soils. Found. 2004; 44, 27-36.

[10] TS Nagaraj, AJ Lutenegger, NS Pandian and M Manoj. Rapid estimation of compaction parameters for field control. Geotech. Test. J. ASTM 2006; 29, 1-10.

[11] S Horpibulsuk, W Katkan and A Naramitkornburee. Modified Ohio's curves: A rapid estimation of compaction curves for coarse- and fine-grained soils. Geotech. Test. J. ASTM 2009; 32, 1-12.

[12] AW Skempton. The colloidal activity of clays. In: Proceedings of the $3^{\text {rd }}$ International Conference on Soil Mechanics and Foundation Engineering. Zurich, 1953; 1, 57-61.

[13] M Budhu. Soil Mechanics and Foundations. $3^{\text {rd }}$ eds. John Wiley \& Sons, 2010. p. 62.

[14] H Nagaraj. 2000, Prediction of Engineering Properties of Fine-grained Soils from Their Index Properties. Ph.D. Thesis, Indian Institute of Science, Bangalore, India, 2000.

[15] R Blotz, L Craig, H Benson and P Boutwell. Estimating optimumm water content and maximum dry unit weight for compacted clays. J. Geotech. Geoenviron. ASCE 1998; 124, 907-12.

[16] D Daniel and C Benson. Water content-density criteria for compacted soil liners. J. Geotech. Eng. ASCE 1990; 116, 1181-90.

[17] D Daniel and Y Wu. Compacted clay liners and covers for arid sites. J. Geotech. Eng. ASCE 1993; 119, 223-37.

[18] ED Foreman and DE Daniel. Permeation of compacted clay with organic chemicals. J. Geotech. Eng. Dn. ASCE 1986; 112, 669-81.

[19] AW Jonhson and JR Sallberg. Factors that Influence Field Compaction of Soil (Compaction Characteristics of Field Eauipment). Highway Research Board Bulletin, 1960, p. 272.

[20] HB Nagaraj and MR Suresh. Influence of clay mineralogy on the relationship of CBR of finegrained soils with their index and engineering properties. Transp. Geotech. 2018; 15, 29-38.

[21] P Punrattanasin. Behavior and strength of loess stabilized by cement and fly ash. In: Proceedings of the $10^{\text {th }}$ National Convention on Civil Engineering. 2005, p. 317-22.

[22] F Maa, J Yang and X Bai. Water sensitivity and microstructure of compacted loess. Transp. Geotech. 2017; 11, 41-56.

[23] D Kim and SS Kang. Engineering properties of compacted loesses as construction materials. KSCE J. Civ. Eng. 2013; 17, 335-41.

[24] P Yodsa-nga, W Gasaluck and P Punrattanasin. Stress distribution in Khon Kaen Loess under spread footing. Electron. J. Geotech. Eng. 2012; 17, 3753-69.

[25] ME Mosallamy, TE Fattah and ME Khouly. Experimental study on the determination of small trainshear modulus of loess soil. HBRC J. 2016; 12, 181-90. 